\title{
Education and the Economy of Attention in Times of (Post-) Pandemic
}

\author{
Siavash Bakhtiar
}

\begin{abstract}
With the Coronavirus crisis, online teaching seems to have become a norm in Higher Education. The essay argues that, although this new pedagogical practice is totally acceptable in times of social distancing, it can lead to something more radical, especially with the strong will of HE institutions to continue this mode of teaching beyond the period of crisis. The normalisation of dematerialised teaching comes as a challenge to academics: it is imbedded in a new form of economy, where attention is a key source of value and labour. The omnipresence of virtual interfaces questions the very fabric of their practice as teachers, especially in humanities, where it can lead to an intensification of the pauperization of teaching staffs, due to forced redundancy. To understand how the normalisation of online teaching after the crisis can be potentially noxious, the essay proceeds by looking at the change of agency of digital tools in teaching contexts, through the concept of pharmakon, developed by Bernard Stiegler, that offers the chance for a critique of this new pedagogical strategy which can be positive during the crisis, but potentially destructive after. This concept leads to a new criteria of judgment of the digital (mode of teaching), which has to be understood as a third way between the optimism of managerial perspectives, always keen to consider information technologies as the perfect catalyst for neo-liberal reforms in education; and the traditional technophobia, proper to a philosophical tradition that, from the Frankfurt School to Giorgio Agamben, apprehends the mediation of technology essentially as a critical regression and a modern form of rationalisation that engenders an immense social and psychic alienation.
\end{abstract}

Keywords: distance teaching - higher education - attention - crisis - pharmakon - technology

\section{Introduction}

When confronted to the question of the replacement of in-class teaching by online delivery, I always remember the Gilles Deleuze aphoristic essay modestly called "If Literature Dies, It Will be Murder," where he states that "if audiovisual media ever replace literature, it won't be as competing means of expression, but as a monopoly of structures (...). It's no matter of comparing different sorts of medium. The choice isn't between written literature and audiovisual media. It's between creative forces (in audiovidual media as well as literature) and domesticating forces" (1995: 131). In other words, the matter of concern is not about the intrinsic qualities of the respective modes of expression, but rather they interact in a complex network of ideological and material forces that constitutes a specific context.

We have all experienced this peculiar context of the Covid-19 Crisis, which has imposed a quasi-global lockdown, with serious consequences when in terms of human interactions. Most of universities in the UK promptly shifted to remote teaching, as a response to the imposed social distancing. In this context, teachers and researchers adapted very quickly. Many of them 
were not "digital natives;" nonetheless, they had to get used, within a few days, to the migration of teaching on different communication platforms, such as Microsoft Teams, Zoom or Panopto, in an great effort to keep the pedagogical continuity until the end of term. However, many of those dedicated academics received a few weeks later, through emails or departmental meetings, a note that the administrators have decided that the online teaching will the privileged option until the end of 2020, and maybe beyond. Many members of staff and unions instantly manifested their scepticism about this managerial choice, which comes as another step to the (neo-liberal) vision of the university it advances and intensity the already existing institutional crisis. ${ }^{1}$ The suspicion was reinforced a few weeks later when the first consequence of these directives for the university community came in the announcement of mass redundancies, recruitment freezes and cuts in programmes. With those drastic measures, it goes without saying that spectre of a standardization of online delivery after the crisis can be perceived as another excuse to accelerate the rampant managerialism that puts higher education on the brink.

In times of crisis, critique is more than essential. Questioning is the essence of the job of an academic - some would say, even her responsibility in difficult times. Therefore, it is important to examine the proliferation of remote teaching, which has important implications for the teachers and the students. The crisis does not provide (yet) a direct opportunity to undo the endemic marketisation of UK universities, it certainly shows the fragility of its fabric. I believe nonetheless that this sort action is necessary: luckily, unions and independent associations of academics are already thinking about ways of a restoration a more accessible and public model of higher education. ${ }^{2}$

Therefore, this essay looks at several aspects of this process. In the first section, it shows how the prolongation - and de facto, the replacement of in-site classes by virtual teaching - might accelerate the proletarianization of teachers, and the growing of class of knowledge workers known as the cognitariat. In the second section, I claim that there is little ground for criticism for this measure during the pandemic: this unprecedented crisis caught everyone unprepared, and it was the universities' responsibility to keep the students safe. However, this new settlement - which combines multitasking, communication of information on platforms owned by private companies, and long-hours in front of the screen - participates fully to what

\footnotetext{
${ }^{1}$ Last spring, academics and members took part in a strike in 74 universities across the UK. It was another illustration of the rapid precariousness of academics, which is a direct consequence of emergence of corporate mentality and market logic within HE institution. The action mainly led by the UCU (University and College Union), that released a report in June 2019, based on the survey led by HESA (Experts in higher education data and analysis) that "give us is an approximate sense of scale. 37,000 fixed-term, mostly hourly paid teaching staff plus another 60-70,000 hourly paid 'atypical academics' represents a lot of casualised teachers circulating in the higher education system." See: https://www.ucu.org.uk/media/10336/Counting-the-costs-of-casualisation-in-higher-education-Jun$19 /$ pdf/ucu_casualisation_in_HE_survey_report_Jun19.pdf

2 Next to the actions led by UCU, the group The Convention for Higher Education has been very active organising to defend Higher Education from market failure. They have organised several videoconferences since May 2020 and have come up with a manifesto in the form a 9 essential points manifesto based around solidarity around the most vulnerable members of staff and eventually restore higher education as a vital public good that should be accessible to all. The members of the Convention are planning to bring their campaign to the Parliament, with a set of demands for the MPs to put the universities on a long-term sustainable footing. See: https://heconvention2.wordpress.com/2020/05/25/new-future-for-he/
} 
thinkers like Yves Citton have called an economy of attention. This concept which gives ground for reflexion on our adjustment to an exponential use of media technologies in our everyday life. Finally, following Bernard Stiegler's notion of pharmakon, I discuss the possibility for a "new" critical theory that perceives objects and virtual activities within their contexts. The pharmacological approach defines them as "cure" or "poison" for the human individuals or societies that interact with/through them. This leads to argue that although technologies are interwoven in the fabric of capital expenditure projects of multinational companies, there is a need to look for an alternative to confront the pessimistic narratives that present always those technologies as alienating instruments.

\section{The University as Atomised Individuals and the Emergence of the Cognitariat}

The quick response of academics to demand to migrate to remote provision, and the accelerated adaptation - via virtual trainings to develop and teach online courses - has pushed paradoxically the managers to believe that in a matter of weeks academics will be ready and happy with this new model for a long period of time, without taking into account the substantive inequality between academics. These differences come in many forms: from the space available in the house to work efficiently - everyone does not have the luxury to have an office at home - to the ability to work with digital tools. By extension, these differences can give ground to a division of labour that will eventually to an atomization of the academic community into individuals, allowing a classic tool of pressure already present in many companies, where failure is, according to the neoliberal framework, understood a consequence of an individual's poor choices rather than the collective responsibility.

Besides, the Covid-19 Crisis comes as another layer to a more latent crisis that has been present for decades. The interest of university managers for technology-enhanced teaching is not new, but the current crisis seems to act as a catalyst to online model of delivery that is already part of the practice of many Higher Education institutions, as a result of the market oriented political choices that have been restructuring of universities, especially in the UK. ${ }^{1}$ It goes without saying that the implementation of a market-oriented ideology, which is aiming at a maximizing profit, is transforming de facto knowledge into a commodity. The traditional argument is that the traditional in-class format is obsolete or anachronistic, and placing business before pedagogy. David Lewin highlights the same point when he asks:

"Is the interest in online education really pedagogical? It seems highly likely that the impetus to develop online education is founded, first and foremost, on economic rather than pedagogic concerns, since online learning is clearly driven by large corporations invested in the proliferation of online technologies, as well as affording extraordinary scalability and restricting the greatest cost in traditional education, the expense of the teachers" (253).

\footnotetext{
${ }^{1}$ In this essay, I focus mainly on UK universities, but there has been a drastic neo-liberal turn of higher education is also present in other European countries, as for instance France with Libertés et Responsabilités des Universités; a reform imposed in 2007 with the objective of adapting public universities to the rules of the Nouveau Management Public (Vinokur 2008). Mutatis mutandis, the reform is usually similar in all the European countries: a shift from a traditional collegiate principle (usually independent from the "outside world") towards a model where the decisions are taken by a board constituted by increasing number of administrators coming from outside the university, and many of them experts in Knowledge Management (Newfield: 70-73).
} 
In a neoliberal paradigm, the work of academics becomes merely "content delivery" to students, who are considered as clients that are looking for credentials that will give them a plus value on the labour market. This narratives has been at the of a larger mechanism, known as cognitive capitalism, which can be defined as a new economy where cognitive activities and information technologies are playing a major part in the production of profit: "the emergence of 'an economy of knowledge' means a strengthening of capitalism by the transformation of a free good into a commodity with an exchange value" (Azam: 111). This new economy is characterised by a shift from the traditional workplaces, such as the factories, to new sectors and such as offices and universities, but also domestic spaces of everyday life - which is now more visible than even, with the social distancing and remote working imposed on a large scale by the Covid-19:

"This mechanism transforms the free and autonomous essence of those activities, through the alienation and the direct domination of individuals, but also by competing with one another and their integration in the techno-structures of biopower. In this context, the university as an autonomous space of production and transmission of knowledge is on the decline. Progressively, it becomes an institution that is potentially at the centre of the capitalist modes of regulation and production" (Cottet, Bernat Zubiri-Rey, Sauvel: 57).

A cognitive capitalist regime, as in the classic liberal economic model, based on division of labour and competition between universities, implies the emergence of a proletariat, known as the "cognitive workers," the "info-proletariat," or the "cognitariat." This new category determines a group of individuals that, on one hand, are selling their labour power for a wage; and, on the other hand, are conscious of their exploitation by a neo-capitalist system. The only different, in comparison to Marx's times, is that today " 'knowledge workers' (...) unlike the employees under capitalism they own both the 'means of production' and the 'tools of production' " (Drucker: 8). These means of production are mainly generated by media technologies, which are the axis of rotation where high tech companies articulate their interaction - some would say insertion - of universities. More than two-third of major digital innovations imply a type of collaboration between private companies and public universities or laboratories called open innovation. This asymmetrical collaboration allows majors companies, such as Microsoft or Google, to give "free access" to their tools, in return of the intellectual property of the inventions, which gives them a great opportunity to expand their monopoly and make their technologies the standard in different sectors( Newfield: 73-74). The consequence is a systematic stratification of the different members of staff between valuable members - researchers that have grants from external companies and agencies, and therefore enjoy a great autonomy within the universities, useful members - lecturers and technicians with experience, usually with an administrative; and finally the disposable members - associates and graduate teaching assistants on fixed-term, variable or zero hours contracts - that constitute the cognitariat of higher education. ${ }^{1}$ Of course, this type of hierarchisation in universities existed before, but it has been intensified with the current

\footnotetext{
${ }^{1}$ As said earlier, the cognitariat is perfectly aware of the situation and the means of its exploitation. In the last months, there have been a great number of academics on precarious contracts that have denounced the university manager's systematic plan an anticipated reduction of hundreds of casualised TA and TF academics, by letting their contracts to expire. Many of them have decided to challenge the financial narrative back this unfair decision, because they consider it is the consequence of bad management and decades of marketisation, rather than the pandemic crisis per se. see also: https://www.ft.com/content/67f89a9e-ac30-47d0-83e7-eba4d1284847
} 
crisis: as mentioned in the introduction, the pauperization of the academic community increased with the systematic slashing of jobs. ${ }^{1}$ This is even more dramatic when it is proven that distance learning is more time-consuming and will demand more preparation from the academics on permanent contract, since it tries to adapt to the needs of the learners:

"This can be observed in the spatio-temporal flexibility of online education: it can take place synchronously (in 'real time') or asynchronously (whenever suits the learner, i.e., self-paced), though the asynchronous component is more characteristic of learning online where learners engage in email, blogs, forums, wikis, audio, video etc. This flexibility can facilitate independence of mind and self-directed attitudes towards education but more negatively, plays into the 'student-as-consumer' attitude" (Lewin: 255).

In the previous lines, I have discussed the notion cognitive capitalism to highlight the emergence of a new class of workers, the cognitariat. In the following section, I would like to introduce another concept that will narrow down the scope and help us to understand better what we all have experienced during the lockdown period, a liminal time where the imposed social distancing has revealed in an unprecedented fashion what is at the centre of cognitive capitalism: attention.

\section{Attention Economy in a Contactless Society}

Lik many people working from home, academics have noticed that this new form of work requires discipline and organisation, in a context where attention becomes rare. The interest in attention is not new, but it remerged in the late 1990s with the exponential use of digital technologies the development of Internet in a globalised market, where "money now flows along with attention" (Goldhaber 1997, emphasis in original). Therefore, in order to understand how cognitive activities become a major subject of profit and domination in a neoliberal regime, I refer in this section to the concept of attention economy, proposed by thinkers such as Yves Citton, and tailor it to the study of the specific case of remote teaching in higher education in times of pandemic, and after. ${ }^{2}$

Citton discuss in his work the necessity to find an alternative to the classic definition of economy, understood as merely a study of the optimisation of the exploitation of rare resources (2014a; 2014b). Accordin to this purely instrumental perspective, one could say that in the age of "liquid "modernity (Bauman 2000), we have reached a quasi-optimal where all interactions are smoothly integrated into flows of data. Despite the fact the fact tha the current ecological crisis demonstrates that the hyper-industrial age is far from being

\footnotetext{
${ }^{1}$ According to UCU, one of the latest and most dramatic action is Bradford College's intention to dismiss 107 academics by 5 August 2020, after a shortfall $£ 2 \mathrm{~m}$ fall in apprenticeship income due to the lockdown. See: https://www.ucu.org.uk/article/10851/Unfair-dismissal-warnings-as-BradfordCollege-announced-plans-to-axe-over-100-staff?list=1676

2 Emmanuel Kessous points out that the "marketisation of attention" can be understood from two different perspectives: "two radically different theoretical approaches based on two fairly compartmentalized disciplines in the social sciences: ergonomics and economics. Whereas in the former, attention is seen as a stock of limited resources that must be preserved, because they are renewed slowly (the problem of usability concerns the use of one's attention), in the latter, attention is seen as a flow. This approach seeks to set up the economic conditions for the exploitation of attention in order to extract value from it." (79) In this essay, I will focus on the former definition.
} 
immaterial: the exploitation of workers to make the devices, the contamination of lands in the extraction of rare mineral. The digital comes at a hight cost.

Paradoxically, the digital age has been often presented, especially in media studies, as a revolution in the progress line of modernity that presents virtual technologies as extensions of man (McLuhan 1999). The study of the economy of attention demonstrates that this new economy, marked by exponential use of digital tools, does no replace the old modes of production and communication, but only "adds another layer of complexity, which is implies a reconfiguration of the ulterior layers, without abolishing them in any way" (Citton 2014a: 9). Said differently, the crisis of attention is just one of the latest coming to complete the litany of the crises of modernity: the ecological, the social, the economic, the viral...

In his seminal book, Pour une écologie de l'attention, ${ }^{1}$ Citton asserts that in order to understand the dept of this crisis, one needs to understand attention as essentially a collective phenomenon, in two senses; first, from an ontological point of view, he reminds us that "individuals do not pre-exist the relations that constitutes them"(45). Secondly, he defends the postulate that:

"[The] attentional resources of each individual allow her to perform a limited number of tasks at a certain time, with relation with the skills she had learned. (...) [The] limited sum of available attention at every moment implies a principle of competition between the different objects that we take into consideration or the quality of the consideration that is dedicated to each of them. (...) What our attention gains quantitatively by taking into consideration different objects simultaneously, we lose qualitatively in the intensity of the attention we dedicate to them separately" (55).

When applied to the practice of online teaching, which require a high level of multi-tasking between giving the instructions, sharing documents, avoiding any connection issues, delegating speech time to the students..., it does not take long to understand that the at the end of the equation, the quality of the teaching will certainly not be the same than in an inclass situation where the capacity for deep attention, necessary for an effective learning, is eroded and replaced by hyper attention that Katherine Hayles defines as "characterized by switching focus rapidly among different tasks, preferring multiple information streams, seeking a high level of stimulation, and having a low tolerance for boredom" (2007: 187).

This new situation offers a good opportunity to think about the type of higher education we want, without falling into the moralism that, since the Frankfurt School, considers all digital technologies and mass media - without distinction - as prostheses of a culture industry that entertains the masses (Adorno 2001). However, the attentional phenomenon is more complex than what thinkers, like Adorno, describe in their work: the position of the viewer is not anymore, a passive one, a victim of a powerful alienating visual industry; rather, attention has to be considered as an active phenomenon where "to look is to labour" (Citton 2014b: 79). ${ }^{2}$

Far from a digital ideology, which would present internet as a neutral network, made of democratic and "free" interactions that would take the peer-to-peer as a standard, those

\footnotetext{
${ }^{1}$ An English version was published in 2016, but in this essay, all the references are from the original French version.

2 Many social scientists have theorised recently what has been coined by Tiziana Terranova as Free Labour: "We call this excessive activity that makes the Internet a thriving and hyper-active medium "free labour" - a feature of the cultural economy at large, and an important, yet unacknowledged, source of value in advanced capitalist societies" (73).
} 
interactions are fundamentally asymmetric: we are not all equals, when it comes to the digital. Like in classic capitalist model, the division of between an elite and a proletariat in mass media is mainly done by the amount of attention one requires for a specific task - just as in the assembly line in Fordist economic factories. As mentioned in the first section, the creation of a cognitariat is mainly due to the very physical of a hyper-industrial type of economy, which is always presented as immaterial, but actually requires a huge amount of material and biological capacities to be inventive enough to produce a product that is attractive enough to catch the attention of the viewers, the clients, the teachers, the students.

Citton also insists on the necessity to invent in education. Following Jacques Rancière's lesson on education, he argues that the essential task of the teachers is not to deliver knowledge, but rather to be inventive enough to catch the student's attention. ${ }^{1}$ The challenge of inventiveness goes hand in hand with novelty: there is a necessity to work with educational allies that participate in the process of creation, since "we see better, because we usually see with" (Citton 2014b: 139, emphasis in original). With what? With colleagues and students: paying attention to a different perspective, learning from it and then trying to adapt it to a new context, in order to convey your own understanding of a subject. With a huge range of objects: books, of course, but also other types of artefacts and technologies, which can facilitate the transfer of knowledge, empowering the students' autonomy and promoting a more democratic educational practice.

This point is very important, since it highlights to consider that in online education, the issue is not the technological devise per se, but the role imposed to them in a specific context of the attention economy. Citton mentions the specific cases of the MOOCS (massive open online courses) to illustrate the ambivalent nature of technology-enhanced teaching. On the one hand, it provides a high-quality teaching to many students who need remote teaching for different reasons - and not only a pandemic. It would be absurd to not recognise that visual technology clearly favours the need of creativity that education needs to be attractive and build up new pedagogical strategies - new forms of evaluation, different format of lectures and seminars, ... - to fit the needs of an ultra-connected generation. But it would be dangerous to see in this mediation as a long-term solution to the new problems of higher education. I have already mentioned the direct effect of this shift on teaching posts: with massive redundancies and the acceleration of the pauperization of university teachers.

Citton also insists on the pauperization of the education experience, in the way that the technological medication does not allow to reproduce two interconnected fundamental features essential to in-class education at a university level. First, the imitation of gesture, which requires that the students must observe, and later repeating, the instructor's action "for real" (Citton 2014b: 145). Secondly, to be able to watch and imitate the instructor, there is a need of corporal presence that allows the affective/sensory/ bodily dimension of the constitution of our individuation (ibid.: 146). Of course, this social proximity is not possible in times of pandemic, and the technology can substitute human presence, and help out to keep a pedagogical continuity; but it would be irresponsible to consider that they can substitute the hands, the voice, the gaze of a teacher.

\footnotetext{
${ }^{1}$ I have mentioned Citton's analysis of Rancière's work on education in a previous essay (Bakhtiar 2018b). See also Citton 2010.
} 
The substitution of technology of human presence, and its interference with the process of individuation has been at the heart of the work of many philosophers. Therefore, I find it important to discuss it in the next section, where I will confront a tradition of critique that is concerned by the rise of technologies in the capitalist (culture) industry and consider de facto most of digital and visual devices as prostheses of a capitalist system or participating to the surveillance apparatus of the state. Contra this technophobic and pessimistic perspective, echoing Bernard Stiegler, I will argue that attention is not a given natural skill that needs to be protected, but rather something that is composed et decomposed with the interaction with other entities, humans and non-humans. ${ }^{1}$

\section{Concerning the Capitalist Pharmacopeia}

The concern about attention is also present in the writings of philosopher Bernard Stiegler who expressed in several occasions the necessity to consider attention in more general terms (économie générale de l'attention) as an essential part, from a very young age, of the socialisation of individuals. After Husserl, Stiegler highlights the fact that the attention processes necessarily go through material dispositifs - from a ritual artefact to an Ipad - that keep part of the artificial memory of a society (Stiegler 2007: 40; 2010: 127). Therefore, he advocates for an approach that analyses the current neoliberal systemic dynamics, that he calls "hypermaterial economy" to contrast with the immaterial narratives (2014: 127).

In philosophy, terminology is important. Consequently, Stiegler' use of the words dispositifs to talk about the technologies, which did not exist at the end of the $19^{\text {th }}$ century and are now taking an active part in the transformation of our societies, is not a trivial act. By choosing this terminology, he chooses his takes part in the argument between the two major currents of the commentators of Michel Foucault: one could be called techno-pessimistic, and the other, techno-enthusiastic. The former perspective is best represented by Giorgio Agamben, and the later by Gilles Deleuze. Both currents refer to Foucault's work on biopolitics and agree on many points in their critique of modernity, especially the one that breaks with the modernist epistemological construction of technological progress (and science) as being essential and neutral with regard to the development of humanity. However, the orientation they give to their reflexions on technology is radically different.

Agamben diagnosis is by far the most pessimistic one: it invites the modern thinkers and favours a definite division between human beings and other entities, since the modern apparatus implies the control of the subject, to the extent of "desubjectification." In What is an Apparatus, he writes:

"It would probably not be wrong to define the extreme phase of capitalist development in which we live as a massive accumulation and proliferation of apparatuses. It is dear that ever since Homo sapiens first appeared. there have been apparatuses; but we could say that today there is not even a single instant in which the life of individuals is not modeled, contaminated, or controlled by some apparatus. (...) What defines the apparatuses that we have to deal with in the current phase of capitalism is that they no longer act as much through the production of

\footnotetext{
${ }^{1}$ It is certainly Bruno Latour who offered the most ambitious theory about the necessity to consider non-human entities as important and necessary actants in the composition of the "social" (Latour 1993, 2005, 2008).
} 
a subject, as through the processes of what can be called desubjectification. A desubjectifying moment is certainly implicit every process of subjectification" $(15,19)$

Deleuze offers a much more enthusiastic definition that focuses on the possibilities modern (media) technological devices can offer in favour of the process of subjectivation:

"The first two dimensions of an apparatus or the ones that Foucault first extracted are the curves of visibility and the curves of utterance. Because apparatuses are like Raymond Roussel's machines, which Foucault also analysed; they are machines that make one see and talk. (...) And finally, Foucault discovered lines of subjectivation. This new dimension has already given rise to so much misunderstanding that it is hard to specify its conditions. More than any other, this discovery came from a crisis in Foucault's thought, as if he needed to rework the map of apparatuses, find a new orientation for them to prevent them from closing up behind impenetrable lines of force imposing definitive contours. (...) And as for Foucault, he sensed that the apparatuses he analysed could not be circumscribed by an enveloping line without other vectors passing above and below: 'crossing the line,' he said, like 'going to the other side'? (...) It is a line of flight. It escapes the previous lines; it escapes from them. The Self is not knowledge or power. It is a process of individuation that effects groups or people and eludes both established lines of force and constituted knowledge. It is a kind of surplus value. Not every apparatus necessarily has it" (2003: 317-318. Emphasis in the original).

In other words, Agamben is looking to what is lost in the digital age, while Deleuze is interested to the potential possibilities that can be gained. I write the potential possibilities to highlight in the passage: "not every apparatus necessarily has it." This statement might look self-evident, but it goes against the grain of a certain nostalgic melancholy that has been present in critical theory, as an important part of its genealogy. Referring to the Deleuzian perspective, I have used the adjective "enthusiastic" rather than "optimistic" to avoid to include Deleuze into a binary logic that would oppose a positivistic tradition that consider techno-science progress as key to humanity's future to a tradition of critique that considers technologies solely as tools eroding some "aura" essential to education and emancipation.

Similarly, Bernard Stiegler also investigates the possibilities offered by the dispositifs, but advocates for a general pharmacological approach of knowledge and considers technologies as pharmaka: that is to say, objects that can be curative or toxic, favour individuation or desindividuation, depending on the way we interact or understand with them (2007: 39-40; 2013: $4 ; 2014: 130$ ). The contribution of such an approach is more than necessary in times of rise of media technologies, and the de facto critique - usual negative - from philosophers and sociologists with regards to them. ${ }^{1}$ It provides a third way - thinking "par le milieu" to use a Deleuzian catchphrase- though to the critical reflexions about the complex relationship between technological devices and the ideological (and scientific) forces that use and are used by them.

Stiegler's theory allows to shape a reflection on education, without falling into a romantic rejection of technology, which is according to him central to the process of humanisation, and therefore of emancipation; in other words, humans are fundamentally technological beings. Confronted to the obstacles of existence, humans had to constantly call on "compensation processes that generate social invention and individuation;" and this compensation cannot be

\footnotetext{
${ }_{1}^{1}$ Stiegler borrows this term from Jacques Derrida, who describes the ambiguous character of writing, that Plato describes as the first pharmakon (Derrida 1981).
} 
done without the participation of devices. Despite the dependence they might create, there is not socialisation without them: "there can be no "origin" no "beginning," no "inside" without exteriorisation and differentiation, without the artifice of technics. From the start, a "default" - and the reliance on technics - is always necessary: un défaut qu'il faut (Stiegler 2003: 152, emphasis in original). Despite this statement, he calls for a new critical theory that highlights the importance of investigating the genealogy of the complex fabric that links technology, attention, and education. ${ }^{1}$ One could read the pharmacological approach as an alternative to the narrative of technological neutrality that consider objects as not neutral tools determined by the will of the user or designer - this user being a humanistic teacher or a capitalist manager. On the contrary, I would say that one should consider technologies used for distance learning as part of a long lines of tools used in the educational practice: just like books or pen and paper. This symmetry does not mean that they all have the same potential, or agency, when they interact with other entities. ${ }^{2}$

Consequently, the pharmacological approach can be sympathetic to the concern of (post-) modern critics like Agamben who warn us about the threat on critical consciousness. However, in contrast with this type of perspective, a pharmacological approach considers that the process of individuation cannot be opposed to alienation. Said differently, the $\mathrm{real} /$ presential cannot be opposed to the virtual: "[the] virtual is opposed not to the real but to the actual. The virtual is fully real in so far as it is virtual" (Deleuze 1994: 208). Stiegler's tour de force is that to offer a new critical discours that gives an alternative to the tradition of critique established by the Frankfurt School, and by post-modernists.

Consequently, he establishes a "new" critical theory that considers that human socialisation is composed by phases of addiction - or desire or drive to use psychoanalytic terminology- to beings and things. ${ }^{3}$ The challenge is to dose out the interaction with those addictive entities, those pharmaka that are potentially a cure or a poison depending on the circumstances. I suggest that this statement is applicable to online teaching; in times of crisis, it has an overall beneficial effect on both teachers and students - in times of social distancing, teaching is better than not teaching. But we must be caution in post-crisis times, when this same pharmakon can be toxic, if we do acknowledge the pharmacological nature of such technology, and we do not

\footnotetext{
${ }^{1}$ David Lewin highlights that it takes part in the polarised debate that has been going between technophiles and technophobes about digitalisation, individual and societal emancipation: "[The debate] has particular resonance with the philosophy of Bernard Stiegler for whom the emergence of human nature and the development of technology are coeval. This is important because it deconstructs the romantic and prelapsarian view of human nature. unsullied by the instrumentalism of homo technicus. If human beings are not, in any meaningful sense prior to technology, then the tensions between technology and education are transformed" (252-253).

2 The term agency has to be understood in the way Latour defines it: "One of them is the precise role granted to non-humans. They have to be actors and not simply the hapless bearers of symbolic projection. But this activity should not be the type of agency associated up to now with matters of fact or natural objects. (...) . Conversely, any study that gives non-humans a type of agency that is more open than the traditional natural causality-but more efficient than the symbolic one-can be part of our corpus, even though some of the authors would not wish to be associated in any way with this approach" (2005: 10).

${ }^{3}$ About addiction, Stiegler writes: "I think addiction is a normal condition and that there are good and bad addictions, in the same way that there are good and bad fictions. (....) In conclusion, any addiction can go sour and trigger instinctive or destructive pulsion, starting with auto-destruction" (2007: 34$35)$.
} 
take care about its effects, without question them, on the process of individuation. as Lewin points out, "[for] Stiegler the mere satisfaction of drives entails infantilization because those drives are given and do not encourage inquiry into their own nature" (261).

I would add that the necessity to care and to be concerned is even more necessary in times of social distancing, that are short-circuiting the process of trans-individualisation necessary to the psychic well-being of individuals and affects their socialisation. In times of pandemic, one should not be concerned about the material and primary organs; the heart, the liver; the lungs...but also the "organa as pharmaka: in other words, the artificial organa without which we are nothing: clothes, glasses and other devices that improve our natural capacities; (...) those pharmaka can also cause ruins, disaster.." (Stiegler 2007: 44). Therefore, one could say that they are not factually always dangerous, but have the potential to be toxic, depending on the circumstances, therefore we should be responsible for the attention we delegate them and consider them legitimately as matters of concern. ${ }^{1}$

\section{Would Prefer Not To...}

If the reader has still some doubt about the fact that some university managers are taking the opportunity of the Covid-19 crisis to push further their neoliberal strategy for the future of Higher Education in the UK, she should read some of the comments of those managers have made in the last months. ${ }^{2}$

I hope that I have proven in this essay that it is fair to oppose this sort of statement. On the base of the material and moral impact on the teachers, who were at the front during the crisis, and also the potential victims of forced redundancy; but also on a more philosophical or ideological bases, since if the online teaching is maintained after the pandemic, it will potentially become a toxic pharmakon that places higher education at the heart of the "symbolic misery," to use Stiegler's terms, "which places the sensory life of the individual under the permanent control of the mass media" (2016: 192). There is no doubt the education is a multifaceted practice that evolves by including new technics, however, as Stiegler has pointed out, many decision makers have purposely or purposely lost sight of the questions of higher education values and purposes. The later are closely linked with the pharmacological questions of caring about beings and things, and the psychological and material consequences

\footnotetext{
1 I have developed a section about the difference between matters of fact and matters of concern, using Bruno Latour's theory, in another essay (Bakhtiar 2018a).

2 For instance the interview given by Prof. Cliff Allan, a former-vice chancellor and eminent Board member of Universities UK, who answered very openly to the question "Will this crisis result in a change to the way universities teach in 2020 , or are we likely to see some changes that endure beyond the time of the pandemic?": "Looking to the future, how can we turn this crisis into an opportunity for change? I hope that we don't fall back into what we were doing before. What can we learn from this fast step-change around teaching and learning that many leaders have wanted to make in universities, but historically haven't been able to? Many people may now be waking up to the opportunities, flexibility, and the different models that might emerge from an online offer. (...) What it could have an impact on is the temporal experience of higher education. Does everything have to be delivered in the traditional academic year? We may feel that this gives us a new model of teaching: any place, anywhere, anytime. In many ways, this is a shock to the system, and sometimes shocks to the system can result in quite rapid change. Many people are using this phrase 'the new normal.' So does this become the normal, as we move forward?" (Allan in Levisohn 2020).
} 
of their toxic (neo-liberal) logic for the teachers, who will be massively pauperized if we all stop paying attention to the pharmacological nature of digital technologies:

"[The] fact of proletarianization is caused by the digital, which, like every new form of tertiary retention, constitutes a new age of the pharmakon. It is inevitable that this pharmakon will have toxic effects if new therapies, new therapeutics, are not prescribed. Such prescriptions are the responsibility of the scientific world, the artistic world, the legal world, the world of the life of the spirit in general and the world of citizens - and, in the first place, of those who claim to represent them." (ibid.: 197).

Indeed, the Coronavirus crisis, as any crisis, is by essence the a time for critique and therefore offers an opportunity for collective and individual choices about the "lines of subjectivation" and "bifurcations," to speak with Deleuze's words, will be co-constitutive of our universities and societies. ${ }^{1}$ Fortunately, as I have already mentioned, there have been a collective actions organised by unions and independent associations mentioned earlier, that are leading campaigns in response to trailing proletarianization that is menacing higher education, the drastic "shocks to the system," to use Prof. Allan's neo-liberal metaphor, imposed to universities the UK.

Finally, what about the individual response to the current situation? It there any mode of resistance at this level? It is certainly the most difficult one, since it implies an implication on the most intimate conditions: On an individual level, the situations are usually much more complicated on a personal and intimate level, especially after this difficult period, when he had to promptly comply to the needs of the pedagogical continuity, but knowing that on the long term the current situation - teaching online - might become toxic. The situation most of academics in times of pandemic reminds me of Bartleby. I see a parallel between the pharmacological condition teachers are in universities, where the current mode of teaching is pushing them to a psychological a material limit, and the stranger protagonist of Herman Melville's eponymous short story, a conscientious clerk in a company in Wall Street, who after a long time of hard work, one day suddenly enters into a state of crisis and decides that would rather not proceed with his regular work; when asked why, he systematically answers: "I would prefer not to" (Melville: 10). This sentence has been the objects of many comments from philosophers, from Derrida to Agamben, ${ }^{2}$ and especially Deleuze who highlights, in his essay Bartleby, ou la formule, the disruptive potential of such an ambiguous answer, which is not a strict refusal, but "Bartleby does not refuse, he simply rejects a nonpreferred (the proofreading, the errands ...). And he does not accept either, he does not affirm a preference that would consist in continuing to copy, he simply posits its impossibility" (92). ${ }^{3}$ Teachers

\footnotetext{
${ }_{1}^{1}$ Stiegler reminds us that "Krisis, which has a long history - in Hippocrates it refers to a decisive turning point in the course of an illness - is also the origin of all critique, of all decision exercised by to krinon as the power to judge on the basis of criteria" (2016: 195).

2 I do not comment in this essay Derrida and Agamben's respective books of the figure of Bartleby, but the reader can find in Gisèle Berkman's excellent essay an extensive analysis of the negative definitions these two thinkers give of of Bartleby. In donner la mort, Derrida understands Melville's tale as another modern version of the biblical story of Abraham's sacrifice; whereas Agamben describes Bartleby as a fictional allegory of the "Muselmann," the central figure in Remnants of Auschwitz that illustrates those in the concentration camps who are deprived of will, spontaneity, and thrown into a vegetative existence (Berkman 2011: 162).

${ }^{3}$ One could see a similitude in the passive resistance of Bartleby and those teachers who, on an individual level, have also rejected a "nonpreferred" when the have taken part on "wildcat" marking
} 
might passively express their pharmacological condition, a negative preference, until the moment his manager recognise the (in)humanity of their condition; echoing the passive resistance of the narrator in Melville's story- at the moment of the clerk's death recognised his critical condition, by finishing his tale with "Ah Bartleby! Ah humanity!" (34). Let's hope we will not have to reach those extreme situations; but for now, let's say that when asked by a manager if she prefers to keep teaching online after the crisis, any academic is entitled to use the Bartlebian formula I would prefer not to as a passive, but still direct, act of resistance.

\section{References}

[1] Adorno, T. (2001). The Culture Industry: Selected Essays on Mass Culture. London ; New York : Routledge

[2] Agamben, G. (2009). What is an Apparatus? And other Essays. D. Kishik and S. Pedatella (transl.). Stanford: Stanford University Press.

[3] Azam, G. (2007). La connaissance, une marchandise fictive. In Revue du MAUSS, 1 (29), 110-126.

[4] Bakhtiar, S. (2018a). Concerning the Apparition of a Mobile Phone in a 17th Century Painting and Its Issuefication. In European Journal of Multidisciplinary Studies, 3(3), 124-131

[5] Bakhtiar, S. (2018b). The Emancipated Student: Rethinking Knowledge, Equality and Democracy. In European Journal Of Social Science Education And Research, 5(3), 32 40.

[6] Bauman, Z. (2000). Liquid Modernity. Cambridge: Polity

[7] Berkman, G. (2011). L'effet Bartleby. Philosophes lecteurs. Paris: Hermann

[8] Citton, Y. (2010). "The ignorant schoolmaster:" knowledge and authority. In Jacques Rancière: Key Concepts. J.-P. Deranty (ed.). Durham: Acumen, 25-37.

[9] Citton, Y. (2014a) Introduction, in L'économie de l'attention. Nouvel horizon du capitalisme? Paris : La Découverte, 7-31.

[10] Citton, Y. (2014b). Pour une écologie de l'attention. Paris : Seuil.

[11] Cottet, D., Zubiri-Rey, J. \& Sauvel, P. (2009). L'émergence du cognitariat face aux réformes universitaires en France. In Multitudes, 39(4), 56-65.

[12] Deleuze, G. (1993). Bartleby ou la formule, In Critique et clinique. Paris : Minuit, 89114.

[13] Deleuze, G. (1994). Difference et repetition. P. Patton (transl.). New York : Columbia University Press

[14] Deleuze, G. (1995). Negotiations: 1972-1990. M. Joughin (transl.), New York: Columbia University Press.

[15] Deleuze, G. (2003). “Qu'est-ce qu'un dispositif ?”. In Deux régimes de fous. Paris : Editions de Minuit, 316-325.

[16] Derrida, J. (1981.) Plato's Pharmacy, Dissemination. B. Johnson (transl.). London: The Athlone Press

[17] Drucker, P.F. (1998). Post-Capitalist Society. New York: Basic Books.

[18] Franck, G. (2013). Capitalisme mental. In Multitudes, 54(3), 199-213.

boycott to protest at Goldsmiths, where five hundred members of staff are at risk of losing their jobs. See: https://www.theguardian.com/commentisfree/2020/jul/01/goldsmiths-sack-casual-staff-examsuniversities-covid-19. 
[19] Goldhaber, M. (1997). The Attention Economy on the Net. In First Monday, 2(4). https://firstmonday.org/ojs/index.php/fm/article/view/519/440

[20] Hayles, K. (2007). Hyper and deep attention: The generational divide in cognitive modes. In Profession, 13, 187-199.

[21] Kessous, E. (2015). The Attention Economy Between Market Capturing and Commitment in the Polity. In Oeconomia, 5 (1), 77-101.

[22] Latour, B. (1993). We Have Never Been Modern. C. Porter (transl.), Cambridge, Mass.: Harvard University Press

[23] Latour. B. (2005) Reassembling the Social. An Introduction to Actor-Network-Theory. New York; Oxford: Oxford University Press

[24] Latour, B. (2008) Where are the Missing Masses, Sociology of a Few Mundane Artefacts Application. In Technology and Society: Building our Sociotechnical Future. D. G. Johnson and J. M. Wetmore (eds.), Cambridge, Mass.; London: The MIT Press, 151-180

[25] Levisohn, E. (2020, April 29). Allan, J. (2020). The future of Higher Education in the UK: COVID19 impact on institutes and students. Studiocity: https://www.studiosity.com/blog/the-future-of-higher-education-in-the-ukcovid19-impact

[26] Lewin, D. (2016). The Pharmakon of Educational Technology: The Disruptive Power of Attention in Education. In Studies in Philosophy and Education, 35, 251-265

[27] McLuhan, M. (1999). Understanding Media: the Extensions of Man. Cambridge, Mass.: MIT Press

[28] Melville, H. (2002). Bartleby, The Scrivener. A Story of Wall-Street. In The Texts of Melville's Short Novels. D. McCall (ed.). New York; London: Norton \& Company. 3-34

[29] Newfield, C. (2009). Structure et silence du cognitariat. In Multitudes, 39(4), 68-78.

[30] Stiegler, B. (1998). Technics and Time I: The Fault of Epimetheus. Stanford: Stanford University Press.

[31] Bernard, B. (2003). Technics of decision an interview. In Angelaki, 8 (2), 151-168

[32] Stiegler, B. (2007). Questions de pharmacologie générale. Il n'y a pas de simple pharmakon. In Psychotropes, vol. 13(3), 27-54.

[33] Stiegler, B. (2010). Taking care of the youth and the generations. Redwood, CA: Stanford University Press.

[34] Stiegler. B. (2013). What Makes Life Worth Living: On Pharmacology. D. Ross (transl.) Cambridge: Polity

[35] Stiegler, B. (2014). L'attention, entre économie restreinte et individuation collective. In L'économie de l'attention : Nouvel horizon du capitalisme?. Y. Citton (ed). Paris : La Découverte.

[36] Stiegler, B. (2016). Automatic society, Londres février 2015. In Journal of Visual Art Practice, 15 (2-3), 192-203.

[37] Terranova, T. (2004). Network Culture: Politics for the Information Age. New York : Pluto Press

[38] Vinokur, A. (2008). La loi relative aux libertés et responsabilités des universités : essai de mise en perspective. In Revue de la régulation. http://journals.openedition.org/regulation/1783 